\title{
PERITENDINITIS CREPITANS AND SIMPLE TENOSYNOVITIS : A CLINICAL STUDY OF 544 CASES IN INDUSTRY
}

\author{
BY \\ A. R. THOMPSON, L. W. PLEWES, and E. G. SHAW \\ From Vauxhall Motors Ltd. and Luton and Dunstable Hospital, Luton, Beds.
}

(RECEIVED FOR PUBLICATION MAY 10, 1951)

This paper deals with simple or traumatic tenosynovitis as distinct from pyogenic or granulomatous affections of the tendon sheaths. Literature on the subject in this country is scanty, and lacking in a clear understanding of the underlying pathology, for although in the pyogenic group a true infection of the tendon sheath is present, this is not always so in simple tenosynovitis, and it is unfortunate that the nomenclature of each should remain the same. Although true tenosynovitis may occur in other regions, the one most commonly affected in simple "tenosynovitis" is the dorsum of the forearm proximal to the wrist joint. Standard works on surgery continue to refer to it as " tenosynovitis", but as the lesion responsible is well above the upper limit of the tendon sheaths themselves, we would prefer the name " peritendinitis crepitans" as being more truly descriptive.

Tenosynovitis is a well known cause of industrial disability, but, except in the mining community, its occupational significance has never been fully appreciated. In certain circumstances, its incidence may be high as during the war years when many people, recruited for work in factories for the first time, were engaged in unaccustomed tasks involving speed and intensity of effort (Reed and Harcourt, 1943 ; Blood, 1942). Tenosynvotis, however, is by no means confined to factory workers. It has been reported among agricultural workers and others (Pozner, 1942 ; Flowerdew and Bode, 1942 ; Taylor-Jones, 1942). The present study is concerned mainly with the condition as it affects the wrist and forearm of the manual worker in industry (peritendinitis crepitans), but an additional series of true tenosynovitis cases involving tendon sheaths in other situations is also considered. If it is not diagnosed and treated promptly, tenosynovitis can cause much needless absenteeism and continuing disability, and at one factory (Vauxhall Motors) employing 12,000 persons medical records in the past show that about 40 cases occur annually, with an average absence of 21 days.

\section{History of Tenosynovitis}

Tenosynovitis appears to have been first observed by Velpeau in 1818 and was later described by him in his Anatomie Chirurgicale published in 1825. $\mathrm{He}$ anticipated plaster immobilization, using a starched crinoline bandage, and, in his book published in 1841, he quoted Boyer who noted that the lesion lay outside the tendon sheath itself, and named it cellulite peritendineuse. Troell (1918), confirmed these observations and suggested the name peritendinitis crepitans", citing areas such as the tendo Achillis and triceps brachii where tenosynovitis occurs but in which no tendon sheath is present. Obolenskaja and Goljanitzki (1927), in a clinical and experimental study, observed 189 cases at a Moscow factory, and they quote Schugajew and Bachrach who noted the incidence of tenosynovitis among tea and tobacco packers at Jaraslaw where repetition movements using a stamping mallet precipitated the condition in the radial extensors and abductors of the wrist and thumb. Moritsch and Blau (1931) produced local inflammatory changes in the tendo Achillis of a rabbit which had been exhausted by faradic stimulation after inoculation with typhoid vaccine and virulent streptococci. This led them to postulate a metastatic theory of origin in support of Felsenreich 
(1928), who noted the incidence of tenosynovitis after exertion following an acute or chronic infection. Biopsy seems to have been performed first by von Frisch (1909) and later by Hauck (1924) who explored cases involving the muscles of the thumb and found serous oedema with congestion of the peri-tendinous areolar tissue but without naked eye changes in the tendons themselves. More recently, the local pathology and histology have been studied in greater detail by Howard (1937) from biopsy material obtained from four acute cases involving the radial extensors at the wrist. He found both tendon and tendon sheath normal to the naked eye, but the musculo-tendinous junction showed a clear, jelly-like oedema with dark-coloured muscle lacking in voluntary contractile power, exhibiting glycogen depletion, and retention of lactic acid suggesting muscle fatigue and exhaustion. Histological examination revealed muscle fibre destruction with interstitial haemorrhage and fibrin deposits which were thought to be the cause of the crepitus. Schugajew and Bachrach found that the incidence of tenosynovitis was related to the speed and intensity of muscle effort. This was most noticeable among fresh workers or veteran employees returning to work after a period of absence. Similar findings were reported by Conn (1931) in the rubber industry, where high speed stereotyped operations involving intensity of effort were necessary; the incidence was affected by economic factors, rising to $0.99 \%$ during the period of economic stress in 1930 and falling to $0 \cdot 15 \%$ when there was full employment. Bunnell (1944) mentions trauma, over-use, and unaccustomed work as the chief causes of tenosynovitis. He refers to an oedematous inflammatory swelling with petechiae of the tendon and its sheath, greatest at the musculo-tendinous junction and extending up into the muscle itself, which may show tears and fibrinous deposits. Sporting activities involving the tendons about the wrist are mentioned as causes by Handfield-Jones (1946) and Heald (1931), the latter pointing out that crepitus is not a constant sign and that the maximum area of swelling and discomfort is well above the tendon sheath itself on the back of the forearm and extending right up into the muscle bellies. Zollinger (1927) studied figures from 929 cases reported to a Swiss insurance company, and stressed the importance of persistent strain rather than trauma as a cause. Only $2 \%$ were due to contusions. Rhodes (1947) was impressed with the effect of gripping, jolting, and vibration movements as precipitating causes, and both he and Zollinger (1927) considered that repeated attacks tend towards a tuberculous infection. Cohen and Reid (1935) mentioned gout in the aetiology, and published a series of seven relapsing or recurrent cases of tenosynovitis in which oxaluria, calculus, or gravel was a constant finding. All failed to respond to treatment until placed on an oxalate-free diet in combination with pulv. borocitratis magnesii co. in drachm doses twice daily. They were inclined to the view expressed by Conn (1931) and supported by Hammer (1934), and Kulowski (1936), that local anatomical considerations have an important bearing on aetiology, the tendons most frequently affected being those subjected to excessive strain at the point where they are crossed by supporting ligaments immediately adjacent to the wrist joint itself. This theory of origin, however, presupposes that the lesion is confined within the limits of the tendon sheaths themselves, a view with which we do not agree.

Other studies reveal conflicting views on both aetiology and treatment. Pozner (1942) reported 20 cases affecting the radial extensors of the wrist among 70 soldiers while harvesting. Treatment was by strapping or a cock-up wire splint with absolute rest for three weeks. Flowerdew and Bode (1942) described 16 cases affecting the extensors of the wrist and fingers among 52 office workers doing farm work, and stressed the importance of early diagnosis and treatment, resolution occurring in about 10 days with strapping and local heat. Reed and Harcourt (1943) observed 70 cases which accounted for $0.54 \%$ of all attendances at an industrial clinic. The causes in order of frequency were strains (40), contusions (13), and repetitive movements (13). Eight of these cases which did not respond to treatment were explored by operation and in each one some constriction of the tendon sheath was found. Treatment was by plaster immobilization combined with passive movements every other day and short wave diathermy. The average disability period in the unexplored cases was 15 days, but it was not stated whether the patients remained at work or not. Howard (1937 and 1938) described two series of 32 and 72 cases respectively, the majority involving the radial extensors of the wrist and abductors of the thumb. The main causes were prolonged exertion after unaccustomed work, resumption of work following absence, and local trauma. He noted the presence of muscle fatigue in all cases, and stressed the importance of absolute immobilization by an unpadded plaster of Paris splint which should also include the thumb. In 34 cases thus treated the average disability was 11.6 days, but if immobilization was inadequate and reliance placed on local heat and physiotherapy, the average disability period rose to 45.7 days. It is not clear whether these patients remained at work while under observation. 


\section{Present Investigation}

Five hundred and forty-four patients were studied between 1941 and 1950. Their occupations were:

$\begin{array}{lllr}\text { Manual workers } & \ldots & \ldots & 444 \\ \text { Agricultural workers } & \ldots & \ldots & 22 \\ \text { Housewives .. } & \ldots & \ldots & 21 \\ \text { Services patients } & \ldots & \ldots & 21 \\ \text { Children under 10 } & \ldots & \ldots & 2 \\ \text { Others . . . } & \ldots & . & 34\end{array}$

Four hundred and ninety were men, 307 of whom were employed in one factory; the remainder, from various sources, were seen in the out-patient department of the Luton and Dunstable Hospital. Those in the factory, most of whom remained at work, were observed in more detail than the hospital cases.

The annual incidence for the combined series is shown in Fig. 1. The abrupt rise after 1945 coincides with a rising intake of new employees in the factory.

\section{Site of the Lesion}

The tendons most frequently affected were the radial extensors of the wrist (extensor carpi radialis longior and brevior) and the abductor pollicis longus or extensor pollicis brevis, either alone or in combination. This is the common lesion found among factory workers, accounting for 419 , or $77 \%$, of the whole series. In five, the condition was bilateral. Although usually referred to as tenosynovitis of the wrist, this condition is not associated with a lesion in the tendon sheath itself but is a true crepitating peritendinitis involving structures higher up in the forearm.

The other cases (125) actually involved tendon sheaths and will be considered subsequently. Details of the site of the lesion in both groups are given in Table A of the Appendix.

\section{Aetiology}

Five main factors appear to be concerned in the aetiology of both groups. In order of frequency these are (1) some occupational change necessitating unaccustomed work (144 cases), (2) a return to work after absence (114 cases), (3) local "strain" either repetitive or a single "strain" (79 cases), (4) direct local blunt trauma (76 cases), (5) simple repetitive stereotyped movement associated with intensity of effort and speed (53 cases).

In four cases only were infective foci, either local or remote, considered to be of aetiological importance, and we have not been able to confirm that

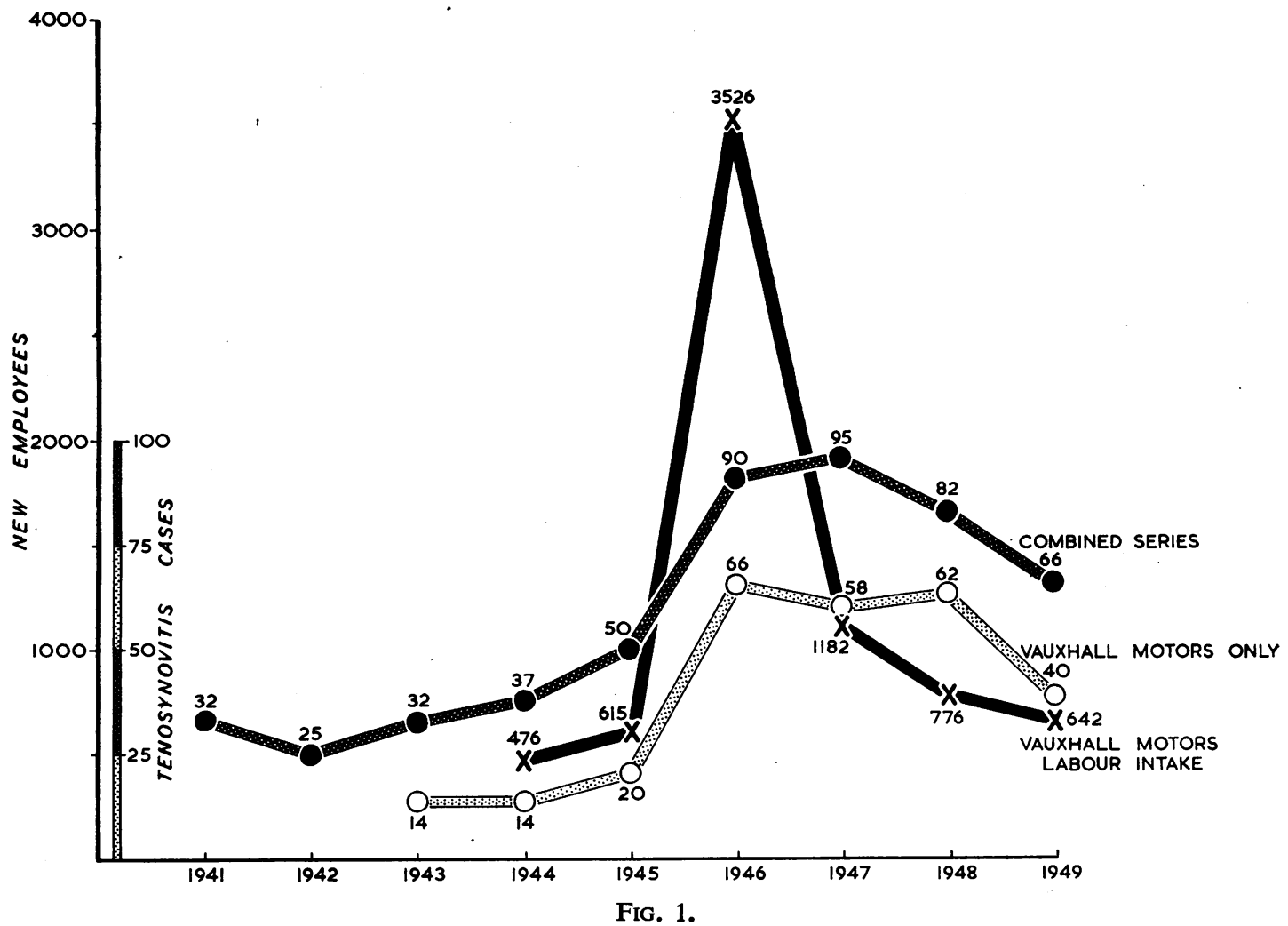


rheumatism, gout or oxaluria are of any importance. Urinary examinations (one specimen only) from 25 resistant or relapsing cases failed to demonstrate the presence of oxalate crystals. A combination of two or more factors was present in 169 cases and the cause was unknown in 78 (for details see Appendix, Table B).

Occupational change accounted for over a quarter of the cases and these fell into four categories. In order of frequency these were a change of job in an old employee, new employees undertaking repetitive work for the first time, ex-Service men returning to civilian work in a factory, and sporting activities. Resumption of work after absence provided $20 \%$ of the total, and arose from three sources; (1) holiday absence, (2) sickness absence, and (3) compulsory absence from work due to the power cut in 1947. The term "strain" signifies unusually heavy manual work requiring strength, dexterity, and speed. A single, sudden, wrenching movement, such as the slipping of a spanner, appeared to be responsible in many cases and suggested to us the possibility of a muscle tear at the junction with the tendon on the back of the forearm. Simple repetitive movement such as filing, hammering, spanner or assembly work was an associated factor in $32 \%$ of all cases.

\section{Peritendinitis Crepitans}

- Signs and Symptoms. - The classical signs and symptoms of tenosynovitis are too well known to be repeated, but in addition to local aching, pain, swelling, tenderness, and crepitus aggravated by pressure or movement, there may be weakness of the muscle-tendon mechanism. Local redness and heat without pyrexia were observed in a few cases, but we have. not been able to confirm the often quoted statement that numbness and a burning pain due to nerve pressure occur in the finger tips. We agree that in early cases symptoms may be present without overt signs, but, in our experience, when once the latter have developed, they cannot be "worked off" as suggested by Bunnell (1944). The swelling is fusiform in shape, 4-12 cm. proximal to the radial styloid on the back of the forearm and well above the upper limit of the tendon sheaths at the wrist. This coincides with the musculotendinous junction where indeed the actual site of the lesion appears to be, the tenderness extending well up the forearm into the muscle bellies in some cases. Crepitus is both palpable and readily audible by stethoscope in doubtful cases and may extend up the forearm as far as the common extensor origin. In character it has been likened to the crunching sound of dry snow or to the creaking of a wash leather. Reproduced on a sound amplifier, the noise resembles the passage of a saw through a thin piece of wood, contraction of the muscle causing a higher pitched note than relaxation. Tracings obtained with a cathode ray oscillograph, using a contact area of 3-16 sq. in. with a constant skin pressure pick-up, show a greatly increased

Normal muscle contraction

FIG. 2.-Cathode-ray oscillograph tracings from a case of peritendinitis crepitans from a contact area presenting maximum crepitus over the back of the forearm approximately at the musculo-tendinous junction. There was well marked crepitus on contraction of the radial extensors of the wrist and A.P.L. and E.P.B. of the thumb. A control tracing taken from the same position over the back of the unaffected forearm is shown for comparison. An increase in amplitude indicating high frequency waves can be observed both during contraction and relaxation on the affected side when compared with the tracing from a normal muscle contraction.
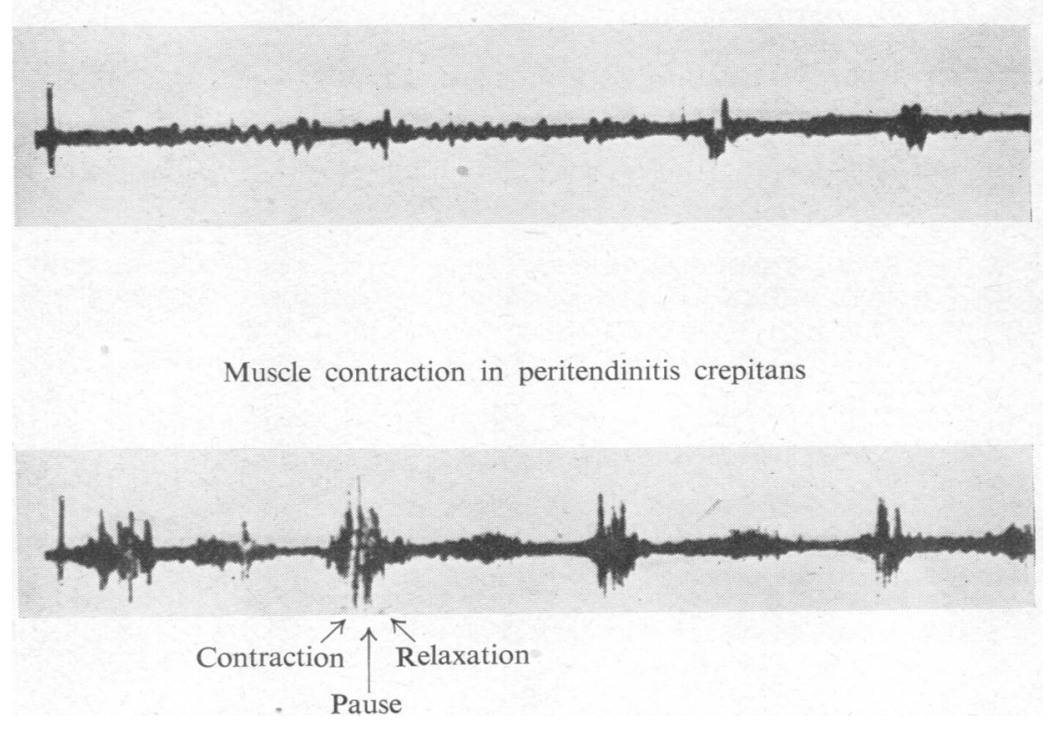
amplitude when compared with the normal (Fig. 2). Daily observation during recovery revealed that the local effusion and tenderness persisted for a variable period after crepitus had subsided, although the latter did not disappear with the development of an effusion. A relapse with recurrence of signs and symptoms shortly after terminating treatment occurred in 93 cases, while $20(5 \%)$ developed second attacks some months or years later, six of these being in the same and 14 in different situations.

\section{Pathology}

Biopsy, in a bloodless field using general anaesthesia, was performed in five cases during the acute stage when the typical signs and symptoms were well in evidence. The findings were as follows :-

Case 1.-A man of 38 employed as a press operator. The cause was unknown. There was no history of trauma and no aetiological factor other than repetitive movement. The abductor pollicis longus, extensor pollicis brevis, and radial extensors at the wrist were involved. Crepitus was well marked over a typical fusiform swelling on the back of the forearm 3 in. above the radial styloid. Biopsy was performed on the fourth day through an incision $1 \frac{1}{2}$ in. long over the area of maximum swelling and tenderness in the region of the musculo-tendinous junction. This revealed oedema with excess of clear free fluid in the subcutaneous tissues. The deep fascia was thickened, and on incising this the subjacent structures bulged through." The perimysium and peritenon were seen to be oedematous and showed dilated blood vessels, and on incision free, serous, straw-coloured fluid collected in the wound. The muscle itself was dark and oedematous but no tears were seen. The adjacent tendons were normal to the naked eye, but as the incision was well above the tendon sheaths at the wrist, the latter were not examined. Portions of the perimysium, peritenon, and muscle at the musculo-tendinous junction corresponding to the area of maximum pain and crepitus were sent for section. The patient was subsequently treated in a dorsal perspex splint for 11 days with complete resolution.

The histological report was as follows :-

"Microscopically the fragment consists of striped muscle and overlying connective tissue. The latter appears oedematous and the vessels prominent and dilated ; a scanty cellular infiltrate is present consisting mainly of histiocytes with a few plasma cells and lymphocytes. The muscle appears normal."

Case 2.-The onset followed unaccustomed work in a man aged 34 who had recently been transferred to work involving hammering up to 800 nails a day. He. developed tenosynovitis of the radial extensors of his right wrist and thumb and showed a well marked, red, oedematous swelling in the usual situation on the back of the forearm. Crepitus could not be felt but was heard by stethoscope. Biopsy was performed on the fourth day through an incision $1 \frac{1}{2}$ in. long over the musculo-tendinous junction. The abductor pollicis longus was most severely involved. The subcutaneous tissue was normal, but the deep fascia was bluish-grey without increased vascularity. On incision of the deep fascia, the underlying tissues did not bulge through but there was a small collection of free, clear fluid. There was a sticky fibrinous deposit between the muscle of the abductor pollicis longus and the deep fascia and between the two short muscles of the thumb. The paratenon of the underlying radial extensors appeared normal to the naked eye, as did the tendon and musculo-tendinous junction of the extensor carpi radialis brevior. Specimens of the musculo-tendinous junction from the abductor pollicis longus and of paratenon from the radial extensors were taken for examination. The patient was subsequently treated in a perspex splint for eight days and made an uninterrupted recovery.

The histological report was as follows :-

"Microscopically the musculo-tendinous junction shows no significant abnormality, and the fragment consists of loose connective tissue which is remarkably vascularized but otherwise normal."

Case 3.-A process foreman 41 years of age developed tenosynovitis of the extensor carpi radialis longior and brevior and of the abductor pollicis longus. The cause was unknown. Biopsy was performed on the fourteenth day, the tendon sheaths being normal in appearance. Portions of the synovial sheath and tendon showed no significant abnormality.

Case 4. - A machine operator aged 36 doing repetition work. The onset was four days after the patient had resumed work after an attack of fibrositis. The abductor pollicis longus and the extensor pollicis brevis were involved together with the radial extensors at the wrist, presenting classical signs of five days' duration. Biopsy was performed on the seventh day. A 2-in. incision centred over the point of maximum tenderness revealed normal skin and subcutaneous tissue. The deep fascia was thickened to $\frac{1}{8}$ in. and was oedematous, and crepitations could still be felt through it. Incision of the deep fascia revealed thickening and oedema of the paratenon over the abductor pollicis longus. There was a shiny fibrinous exudate between the paratenon of the abductor pollicis longus and the extensor carpi radialis longior and brevior.

Pieces of deep fascia, paratenon, and the musculotendinous junction of the abductor pollicis longus were sent for section. The tendons of the extensor carpi radialis longior and brevior appeared normal. The pathologist's report was as follows :-

" Microscopically the fragments of deep fascia consist of loose, rather vascular connective tissue showing no significant abnormality, and that of paratenon is composed of loose connective tissue including a number of widely separated bundles of muscle fibres. The section of the musculo-tendinous junction consists of muscle and tendon, together with the paratenon and shows a marked increase in cellularity due to actively proliferating fibroblasts." 
The local lesion in peritendinitis crepitans is certainly not in the tendon sheath or tendon itself, but at the musculo-tendinous junction well above the upper limit of the tendon sheath at the wrist. Fibrinous deposit or extravasation of blood, so often quoted as the cause of crepitus, was found in two cases, but the underlying mechanism of this sign is not clear to us. Muscle fatigue and weakness may be present, and is probably caused by pain, but we have had no opportunity of exploring a case due to "strain" or of confirming the existence of a muscle tear.

\section{Treatment}

The different methods of treatment used were plaster immobilization, perspex splinting, strapping, physiotherapy, and local support with or without external applications to the skin. In many instances, a combination of these methods was used. Until 1946, plaster immobilization for three weeks, using either a dorsal slab or an unpadded scaphoid type of plaster which included the thumb, was the usual method of treatment. This was later replaced by partial immobilization by strapping carried well up the forearm with the wrist in extension in conjunction with short-wave therapy, and finally by perspex splinting to the wrist and thumb, either alone or combined with short-wave therapy. The last two methods were evolved as a result of industrial experience, and yielded better results. With the exception of 46 patients $(10.9 \%)$ who ceased work, routine follow-up examinations were carried out wherever possible, and in calculating the relapse rate and the incidence of second attacks, some allowance must be made for the fact that 139 , or $33 \%$ were given selected work while under treatment.

By "relapse" is meant a recurrence of signs and symptoms occurring shortly after cessation of treatment. The "lag period", or number of days elapsing between the onset of symptoms and the beginning of treatment, was recorded in an endeavour to correlate this factor with prognosis and methods of treatment.

Immobilization in an unpadded plaster of Paris splint for three weeks is a common method of treatment for tenosynovitis at the wrist. The plaster should include the thumb because of the frequency with which the abductors and extensors to the thumb are involved. When only a dorsal slab was applied, we had many failures. For the manual worker plaster possesses certain disadvantages, because the use of the thumb is too restricted, the gripping power is limited, and contact with oil, water, and wet processes generally is not possible. In the factory series, $25.5 \%$ of patients so treated had to cease work for an average period of $26 \cdot 4$ days, and of those who were able to remain, $74 \%$. required some selected occupation for between four and five weeks. On an average, immobilization was found to be necessary for four weeks because the relapse rate on routine removal of the plaster on the twenty-first day proved to be disappointingly high, and, in the factory series, was $44 \%$. Relapses usually occurred between the third and the ninth days. Bunnell (1944) warns against prolonged immobilization which leads to the formation of adhesions. He advises that movements be carried out daily through a full range after the first week or two in plaster. Reed and Harcourt (1943) practised this method in their series, the plaster being removed every second day for passive movements and diathermy. Their average disability period was 15 days, although in 14 of their 62 cases this continued for an average of 39 days.

As with other methods of treatment, there was no relationship between the lag period before beginning treatment and the recovery rate in days, which suggests that delay in obtaining treatment does not influence the prognosis adversely.

The results in a small series of cases (11) treated with simple strapping were distinctly better in every way, with one relapse and an average recovery period of 20 days. Most of these cases, however, occurred among the hospital group and had already received some preliminary treatment elsewhere so that these results must be accepted with reservation. Nevertheless, they suggest that incomplete immobilization is an advantage rather than a disadvantage in treatment. A further series of 83 patients treated by short wave therapy in combination with strapping showed a relapse rate of $13 \%$, but resolution was more rapid, averaging 13.4 days. Only one of these patients lost time away from work, although $47 \%$ required selected work for an average of 15 days.

Perspex splinting, either alone or in conjunction with short wave therapy, was employed in 116 cases and proved to be the most effective of all methods used, yielding a combined relapse rate of $6 \%$ and an average recovery period of just over 12 days. The splint was easily removed, and allowed daily examination, active or passive movements, and short wave therapy. The necessity for selected work was reduced to a minimum because the plastic material is light in weight, clean, impervious to oil and water, and can be used repeatedly, being remoulded to fit each successive patient. The splint (see Figs. 3, 4, and 5), which is easily made from blank shapes cut from $\frac{1}{8}$ in. thick perspex sheeting, is bent under heat using a naked oxy-acetylene flame or an electric oven, and is moulded accurately to the patient's forearm, wrist, and thumb with the 


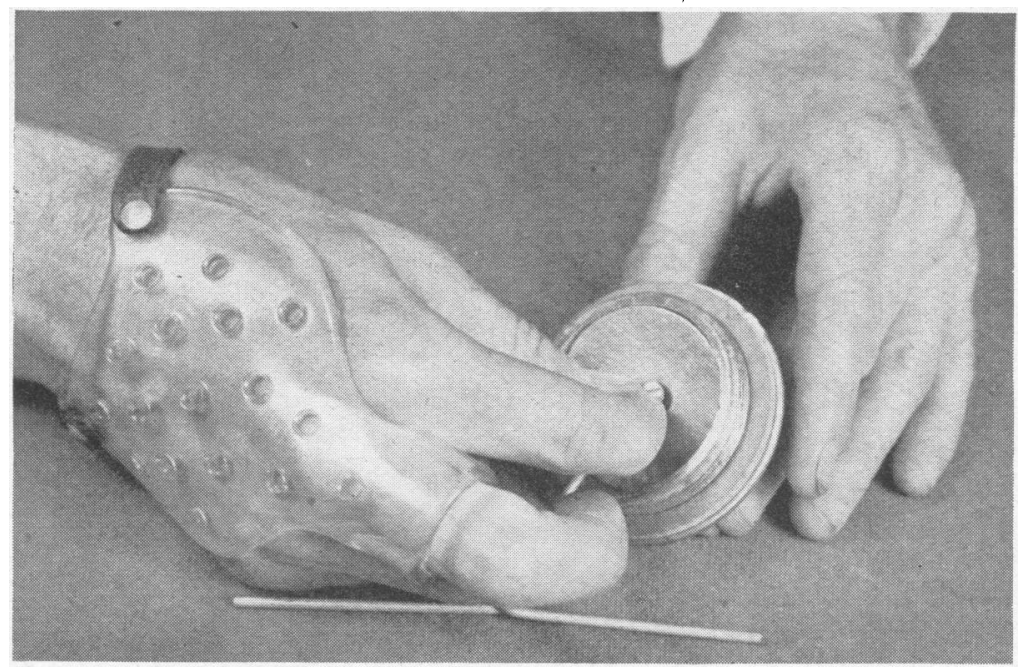

FIG. 3.-Perspex splint with ring extension employed in cases of tenosynovitis affecting the extensor tendons of the fingers.

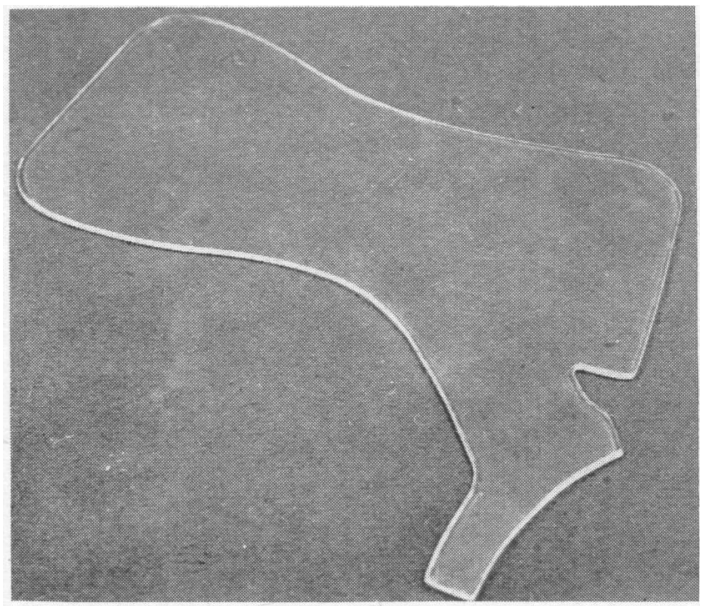

FIG. 4.-Blank shape of the splint before moulding.

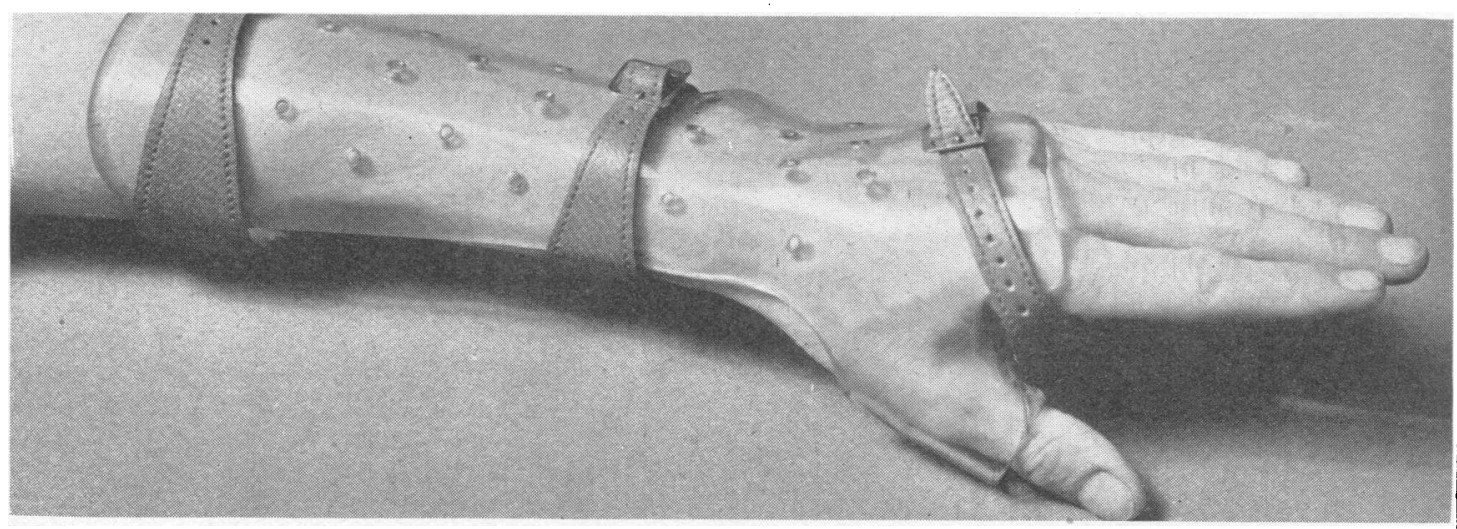

Fig. 5.- Moulded perspex splint in position over the dorsum of the forearm, wrist, and thumb joints for use in the classical form of tenosynovitis (peritendinitis crepitans) affecting the radial extensors of the wrist and abductors and extensors of the thumb.is 
latter in the half-abducted position. It is secured to the forearm and hand by straps and is perforated for lightness and ventilation.

Twenty of the more severe factory cases were treated by perspex splinting and short wave therapy. The relapse rate was $11 \%$ and the average recovery period 14.2 days. Selected work was necessary for 15 of the patients. Contrary to the view expressed by Howard (1937), we are of opinion that short wave or other methods of local heat therapy have a definite place in treatment, in particular in the more resistant and severe forms of crepitating peritendinitis, provided that immobilization is employed but is not prolonged and absolute.

The 64 factory cases treated while at work with perspex splinting alone or in combination with early full range movements of the wrist and thumb every other day, recovered on an average in 10.5 days with a relapse rate of $6 \cdot 2 \%$, selected work being necessary for $21(33 \%)$. The 31 hospital out-patient cases treated by initial immobilization in a perspex splint for eight days before beginning movement, took 15 days to recover with a relapse rate of $3 \%$. This suggests that daily full range movements started early are an advantage in treatment.

\section{Simple Tenosynovitis Involving Tendon Sheaths Only}

One hundred and twenty-five patients were observed. Among 66 of these cases the extensors of the fingers, either singly (commonly the extensor indicis proprius), or more than one (extensor communis digitorum) were involved. The tibialis anticus was affected in 21 cases, only two occurring in factory workers, and the peroneal tendons in 10, all of which were hospital out-patients. Seven out of the 10 peroneal cases occurred in women. We have not encountered this condition among workers on pedal-operated machines, neither have we observed tenosynovitis in the upper extremity among typists, sewing or comptometer machine operators to which reference has been made in the literature. No case affecting the tendo Achillis was seen.

Direct local trauma, such as a blow on the back of the hand, occurred with equal frequency in both the factory and hospital series, and was the usual cause where the condition was confined to the extensor tendons of the fingers. But this condition may arise spontaneously where the work involves repetitive stereotyped movement associated with speed. No case of secondary tuberculous infection occurred, and only two of our series developed De Quervaine's disease as a sequel. We have not seen trigger finger or thumb develop as a result of tenosynovitis, neither have any of our chronic or relapsing cases of true tenosynovitis developed constriction within the tendon sheath necessitating exploration as in Reed and Harcourt's series

Case 1.-The patient was a man aged 21 employed as a polisher. The onset was due to trauma following a blow over the back of the hand. He developed tenosynovitis of the extensor communis digitorum of the right middle finger, with well marked crepitus and swelling the day after injury. An incision 1 in. long was made over the site of the lesion on the dorsum of the hand on the second day. The skin was bruised, and the subcutaneous tissue and paratenon were oedematous with increased vascularity and an excess of straw-coloured fluid in the wound. The underlying tendon was normal in appearance and no blood was seen either in the tendon sheath or in the region of the paratenon. There was bruising of subcutaneous tissue over the interossei and of the interossei themselves. Portions of the paratenon and tissue adjacent to the interosseus muscle were sent for section, and the patient was treated by perspex splinting for 10 days and recovered uneventfully.

The histological report was as follows :-

"The fragment of paratenon consists of vascularized and congested loose connective tissue. Scattered throughout are numerous large swollen histiocytes together with a few plasma cells and lymphocytes which are most marked in relation to the vessels. The fragment of tissue adjacent to the interosseus muscle consists of vascularized and congested loose connective tissue with a similar but less marked infiltrate to the above."

The methods of treatment employed were similar to those described for peritendinitis crepitans and the results are summarized in Table $C$.

These results suggest that in the treatment of true tenosynovitis, as in peritendinitis crepitans, rigid fixation in plaster or inadequate immobilization with strapping are attended with a high relapse rate and delayed resolution. The employment of short wave therapy, however, in combination with strapping or perspex splinting considerably reduced the period of disability and the relapse rate. Of 44 cases thus treated, only one lost time from work, although selected work was necessary for 15 of them.

Where the lesion affected the digital extensors over the dorsum of the hand or finger, immobilization only as far as the proximal inter-phalangeal joint was all that was necessary, and for this purpose the ring type of splint illustrated was employed, the patient being frequently able to continue his normal work.

\section{Summary}

A clinical analysis of 544 cases of simple or traumatic tenosynovitis has been made with particular reference to occupational factors and to treatment. Of these $77 \%$ involved the radial extensors and abductors of the wrist and thumb. There were five main factors in the aetiology: occu- 
pational change necessitating unaccustomed movement $(27 \%)$; resumption of work after absence $(21 \%)$; repetitive stereotyped movement $(16.5 \%)$; direct local trauma (14\%); and local "strain" $(14 \%)$.

The literature on tenosynovitis has been reviewed, and the pathology discussed. In five patients a biopsy was performed.

The term "tenosynovitis" applied to the usual crepitating condition found proximal to the wrist joint is a misnomer. The actual site of the lesion is well above the upper limit of the tendon sheaths at the wrist which are unaffected, the local pathology suggesting that it is essentially a peri-myotendinitis involving the musculo-tendinous junction higher up in the forearm. It is suggested that "peritendinitis crepitans" or " peri-myotendinitis crepitans" is a more accurate description for this condition and should replace the name tenosynovitis. In other situations, however, true tenosynovitis may be precipitated by local trauma or other agencies, the lesion in this event being dependent upon the presence of a tendon sheath in situ.

The pathology, which is obscure, is not related to local anatomical peculiarities and appears to be an inflammatory response to strain in particular groups of muscles, tending to occur in certain susceptible individuals. The prognosis is good, and during treatment cessation from work is neither desirable nor necessary. Rigid immobilization in plaster of Paris is contraindicated, and is associated with a high relapse rate. Where the lesion is situated proximal to the wrist, as in peritendinitis crepitans, treatment by immobilization should always include the thumb because of the frequency with which the latter is involved. This is best effected by means of a detachable perspex splint which permits very slight movement within the splint and will allow early passive movements to be given every other day. Short wave therapy is also valuable in the treatment of certain resistant cases and can conveniently be given when a detachable splint is in use. The splint may be gradually discarded over several days, the patient can frequently continue at his normal work, and relapses are infrequent. Under such a régime, subsidence of signs and symptoms may be expected by the eighth or ninth day of treatment irrespective of delay in beginning treatment.

We are indebted to Dr. Bradley Watson, pathologist to the Luton and Dunstable Hospital, for the histological reports on sections, and to Dr. P. M. Bennett, Medical Officer to Vauxhall Motors Ltd., for his advice and assistance. Our thanks are also due to Mr. F. Trussell, foreman of the Vauxhall Rehabilitation Workshop, and his staff for the development and manufacture of the perspex splint.

\section{REFERENCES}

Blood, W. (1942). Brit. med. J., 2, 468.

Bunnell, S. (1944). "Surgery of the Hand." Philadelphia.

Cohen, H., and Reid, J. B. (1935). Lpool. med. chir. J., 73, 248.

Conn, H. R. (1931). Ohio St. med. J., 27, 713.

Felsenreich, F. (1928). Dtsch. Z. Chir., 211, 175.

Flowerdew, R. E., and Bode, O. B. (1942), Brit. med. J., 2, 367.
Frisch, O. von (1909). Arch. klin. Chir., 89, 823.

Frisch, O. von (1909). Arch. Klin. Chir., 89, $140,353$.

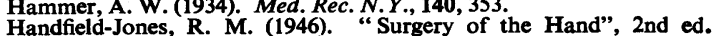
Edinburgh

Hauck, G. (1924): Arch. klin. Chir., 128, 815.

Heald, C. B. (1931). "Iniuries and Sport." London.

Howard, N. J. (1937). J. Bone Jt Surg., 19, 447.

(1938). Amer. J. Surg., 42, 723.

Kulowski, J. (1936). J. Mo. med. Ass., 33, 135

Moritsch, P., and Blau, A. (1931). Dtsch. Z. Chir., 231, 550.

Obolenskaja, A. J., and Goljanitzki, J. A. (1927). Ibid., 201, 388.

Pozner, H. (1942). J. R. Army med. Cps, 78, 142.

Pozner, H. (1942). J. R. Army med. Cps, 78, 142. J. Surg., 62, 392.

Reed, J. V., and Harcourt, A. K. (1943)

Rhodes, R. L. (1947). Ibid., 73, 248. .

Taylor-Jones, T H. E. (1942). Brit. med. J.,
Troell, A. (1918). Ditsch. Z. Chir., 143, 125.

Velpeau, A. (1841). "Leçons orales de clinique chirurgicale faites à l'Hôpital de la Charité ", Vol. 3, p. 94 . Paris.

Zollinger, F. (1927). Arch. orthop. Unfall.-Chir., 24, 456. 


\section{A P P E N D I X}

TABLE A

SITE OF THE LESION

\begin{tabular}{|c|c|c|c|c|c|c|c|c|c|}
\hline \multicolumn{7}{|c|}{ Type of Tenosynovitis } & $\begin{array}{l}\text { Vauxhall } \\
\text { Motors }\end{array}$ & $\begin{array}{l}\text { Luton and } \\
\text { Dunstable } \\
\text { Hospital }\end{array}$ & $\begin{array}{c}\text { Combined } \\
\text { Series }\end{array}$ \\
\hline \multicolumn{7}{|c|}{$\begin{array}{l}\text { Peritendinitis Crepitans } \\
\text { Radial extensors of the wrist (extensor carpi radialis longior and brevior) } \\
\text { Abductors and extensors of the thumb (abductor pollicis longus and } \\
\text { extensor pollicis brevis) } . \\
\text { Radial extensors of the wrist and abductor pollicis longus and extensor }\end{array}$} & $\begin{array}{r}55 \\
94 \\
53 \\
38 \\
4\end{array}$ & $\begin{array}{l}88 \\
31 \\
\frac{55}{1}\end{array}$ & $\begin{array}{r}143 \\
125 \\
108 \\
38 \\
5\end{array}$ \\
\hline $\begin{array}{lc} & \text { True } T e \\
\text { Extensors of the fingers } & \ldots \\
\text { Tibialis anticus } \quad . & \ldots \\
\text { Flexors of the wrist } \ldots & \ldots \\
\text { Flexors of the fingers } . . & \ldots \\
\text { Extensors of the toes } \ldots & \ldots \\
\text { Peroneal tendons } . & \ldots \\
\text { Extensors and flexors of the wrist } \\
\text { Ulnar extensors of the wrist ... } \\
\text { Extensors of the wrist and fingers } \\
\text { Flexors of toes.. } \\
\text { Extensors of fingers and thumb }\end{array}$ & $\begin{array}{l}\text { nosy } \\
\cdots \\
\cdots \\
\cdots \\
\cdots \\
\cdots \\
\cdots \\
\cdots \\
\cdots \\
\cdots\end{array}$ & $\begin{array}{l}\text { vitis } \\
\cdots \\
\cdots \\
\cdots \\
\cdots \\
\cdots \\
\cdots \\
\cdots \\
\cdots \\
\cdots\end{array}$ & $\begin{array}{l}\cdots \\
\ldots \\
\cdots \\
\cdots \\
\cdots \\
\cdots \\
\cdots \\
\cdots \\
\cdots \\
\cdots\end{array}$ & $\begin{array}{l}\cdots \\
\ldots \\
\ldots \\
\ldots \\
\cdots \\
\ldots \\
\ldots \\
\ldots \\
\cdots\end{array}$ & $\begin{array}{l}\ldots \\
\ldots \\
\ldots \\
\ldots \\
\ldots \\
\ldots \\
\ldots \\
\ldots \\
\ldots\end{array}$ & $\begin{array}{l}\cdots \\
\cdots \\
\cdots \\
\cdots \\
\cdots \\
\cdots \\
\cdots \\
\cdots \\
\cdots\end{array}$ & $\begin{array}{r}46 \\
2 \\
5 \\
4 \\
1 \\
-1 \\
1 \\
1 \\
1 \\
1\end{array}$ & $\begin{array}{r}20 \\
19 \\
2 \\
4 \\
6 \\
10 \\
1 \\
- \\
- \\
-\end{array}$ & $\begin{array}{r}66 \\
21 \\
7 \\
8 \\
7 \\
10 \\
2 \\
1 \\
1 \\
1 \\
1\end{array}$ \\
\hline Total .. & .. & $\ldots$ & $\ldots$ & .. & $\ldots$ & . & 307 & 237 & 544 \\
\hline
\end{tabular}

TABLE B

AETIOLOGY

\begin{tabular}{|c|c|c|c|c|c|c|c|c|c|c|}
\hline \multicolumn{8}{|c|}{ Aetiology } & \multirow[t]{2}{*}{$\begin{array}{c}\text { Vauxhall } \\
\text { Motors }\end{array}$} & $\begin{array}{l}\text { Luton and } \\
\text { Dunstable } \\
\text { Hospital }\end{array}$ & \multirow[t]{2}{*}{$\begin{array}{c}\text { Combined } \\
\text { Series }\end{array}$} \\
\hline \multicolumn{8}{|c|}{ Main Causes Only } & & \multirow[b]{2}{*}{16} & \\
\hline Change of & job & .. & .. & $\cdots$ & $\cdots$ & $\cdots$ & & 54 & & 70) \\
\hline \multirow{2}{*}{$\left.\begin{array}{l}\text { Unaccustomed } \\
\text { work }\end{array}\right\}$} & oyee & .. & $\ldots$ & $\ldots$ & $\ldots$ & $\ldots$ & . & 30 & $\begin{array}{l}16 \\
26\end{array}$ & \multirow{2}{*}{$\left.\begin{array}{l}70 \\
56\end{array}\right\}$} \\
\hline & civilian & worl & .. & . & . & . & $\ldots$ & 11 & 3 & \\
\hline Sporting a & ctivities & s... & .. & .. & .. & .. & . & 2 & \multirow{2}{*}{$\begin{array}{l}2 \\
3\end{array}$} & $\begin{array}{r}14 \\
4\end{array}$ \\
\hline \multirow{3}{*}{$\begin{array}{l}\text { Resumption of } \\
\text { work after } \\
\text { absence }\end{array}$} & ave & $\ldots$ & $\ldots$ & $\cdots$ & $\cdots$ & $\cdots$ & $\cdots$ & 47 & & \multirow{2}{*}{$50\}$} \\
\hline & & . & .. & . & .. & . & .. & 36 & 13 & \\
\hline & osure ( & power & :ut) & $\ldots$ & . & . & .. & 15 & - & $\left.\begin{array}{l}49 \\
15\end{array}\right\} 114$ \\
\hline "Strain" (local) & .. & .. & .. & $\ldots$ & $\ldots$ & 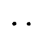 & . & 39 & 40 & $79^{\circ}$ \\
\hline Trauma (direct local) .. & . & .. & . & . & . & . & .. & 41 & 35 & 76 \\
\hline Repetitive movement & $\ldots$ & . & .. & . & . & . & . & 30 & \multirow{2}{*}{$\begin{array}{l}23 \\
76\end{array}$} & 53 \\
\hline Cause unknown & . & . & . & $\cdots$ & $\cdots$ & . & $\cdots$ & 2 & & 78 \\
\hline & & & & & & & & Total & - & 544 \\
\hline \multicolumn{8}{|c|}{ Two or More Factors } & & \multirow[b]{2}{*}{1} & \\
\hline \multicolumn{8}{|c|}{ Trauma and repetitive movement $\ldots$} & 7 & & - \\
\hline "Strain" and repetitive mo & vemen & & .. & .. & . & . & . & 9 & 3 & - \\
\hline Change of job and repetitiv & e move & ment & . & . & & (2) & . & 41 & 4 & - \\
\hline Absence and repetitive mov & ement & . & . & . & $\ldots$ & . & . & 37 & 2 & - \\
\hline Absence, infection, and repe & etitive $r$ & mover & ent & . & & $\ldots$ & . & 7 & 1 & - \\
\hline Absence and "strain" & . & .. & . & . & $\ldots$ & . & .. & 10 & 2 & - \\
\hline Absence and trauma (local) & $\ldots$ & .. & $\ldots$ & . & 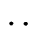 & $\ldots$ & .. & 9 & 1 & - \\
\hline Absence and change of job & .. & . & . & .. & $\ldots$ & .. & $\ldots$ & 11 & 1 & - \\
\hline Infection and repetitive mov & vement & $\ldots$ & $\ldots$ & .. & $\ldots$ & .. & 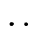 & 10 & - & - \\
\hline Rheumatic or "gouty" (do & ubtful) & & .. & . & .. & $\ldots$ & 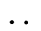 & 1 & - & - \\
\hline Change of job and infection & .. & $\ldots$ & .. & $\ldots$ & .. & .. & . & 2 & - & - \\
\hline Trauma and infection. . & .. & .. & $\ldots$ & . & .. & $\ldots$ & $\ldots$ & 3 & - & - \\
\hline Trauma and change of job & .. & $\ldots$ & .. & .. & .. & .. & .. & 7 & - & - \\
\hline
\end{tabular}


TABLE C

SUMMARY OF METHODS OF TREATMENT OF PERITENDINITIS

\begin{tabular}{|c|c|c|c|c|c|c|c|c|c|}
\hline \multirow[b]{3}{*}{ Individual Series } & \multicolumn{9}{|c|}{ Wrist Only } \\
\hline & \multicolumn{2}{|c|}{ No. of Cases } & \multirow[b]{2}{*}{ Total } & \multicolumn{2}{|c|}{ Relapses } & \multicolumn{2}{|c|}{$\begin{array}{l}\text { Recovery Rate } \\
\text { (in days) }\end{array}$} & \multicolumn{2}{|c|}{ Combined Series } \\
\hline & $\begin{array}{l}\text { Vauxhall } \\
\text { Motors }\end{array}$ & \begin{tabular}{|l|} 
Luton \\
and \\
Dun- \\
stable \\
Hospital
\end{tabular} & & $\begin{array}{l}\text { Vauxhall } \\
\text { Motors }\end{array}$ & $\begin{array}{l}\text { Luton } \\
\text { and } \\
\text { Dun- } \\
\text { stable } \\
\text { Hospital }\end{array}$ & $\begin{array}{l}\text { Vauxhall } \\
\text { Motors }\end{array}$ & \begin{tabular}{|} 
Luton \\
and \\
Dun- \\
stable \\
Hospital
\end{tabular} & $\begin{array}{c}\text { Relapse } \\
\text { Rate }\end{array}$ & $\begin{array}{c}\text { Recovery } \\
\text { Rate } \\
\text { (in days) }\end{array}$ \\
\hline 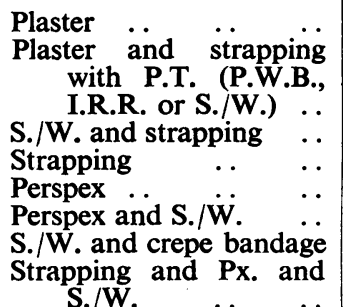 & $\begin{array}{c}10^{*} \\
79 \\
4 \\
64 \\
20 \\
9^{* *} \\
3\end{array}$ & $\begin{array}{r}-4 \\
7 \\
31 \\
1 \\
-\end{array}$ & $\begin{array}{r}177 \\
\\
10 \\
83 \\
11 \\
95 \\
21 \\
9 \\
6\end{array}$ & \begin{tabular}{|c|}
$22(44 \%)$ \\
\\
$8(80 \%)$ \\
$10(12 \cdot 6 \%)$ \\
1 \\
$4(6 \cdot 2 \%)$ \\
$2(11 \%)$ \\
$1(11 \%)$ \\
$?$
\end{tabular} & $\begin{array}{c}43(34 \%) \\
1(25 \%) \\
1(3 \%) \\
- \\
?\end{array}$ & $\begin{array}{l}29 \\
\\
28 \\
13 \cdot 1 \\
23 \\
10 \cdot 5 \\
14 \cdot 2 \\
12 \cdot 3 \\
19\end{array}$ & $\begin{array}{l}26 \\
\overline{20} \\
17 \cdot 6 \\
15 \\
- \\
18\end{array}$ & $\begin{array}{l}36 \cdot 7 \% \\
\\
80 \% * \\
13 \% \\
9 \% \\
5 \cdot 2 \% \\
11 \% \\
11 \% \\
-\end{array}$ & $\begin{array}{l}28 \\
13 \cdot 4 \\
20 \\
12 \\
13 \cdot 9 \\
12 \cdot 3 \\
\\
18 \cdot 5\end{array}$ \\
\hline $\begin{array}{llll}\operatorname{Others}^{5 .} & \cdots & \cdots & \cdots\end{array}$ & 4 & 3 & $\stackrel{0}{7}$ & $?$ & $?$ & $19 \cdot 5$ & 17 & 二 & $18 \cdot 4$ \\
\hline \multirow[t]{2}{*}{ Totals } & 244 & 175 & 419 & - & - & - & - & - & - \\
\hline & & & & \multicolumn{4}{|c|}{ Tendon Sheaths Only } & & \\
\hline $\begin{array}{lrrr}\text { Plaster } & . & \ldots & \ldots \\
\text { Perspex } & . & . & . \\
\text { S./W. } & \text { or } & \text { P.W.B. } & \text { and }\end{array}$ & $\begin{array}{l}17 \\
14\end{array}$ & $\begin{array}{r}33 \\
3\end{array}$ & $\begin{array}{l}50 \\
17\end{array}$ & $\begin{array}{l}7(41 \%) \\
1(7 \%)\end{array}$ & $\left|\begin{array}{c}11(34 \cdot 4 \%) \\
1\end{array}\right|$ & $\begin{array}{l}24 \cdot 3 \\
10\end{array}$ & $\begin{array}{l}25 \cdot 7 \\
17\end{array}$ & $\begin{array}{l}36 \% \\
11 \cdot 7 \%\end{array}$ & $\begin{array}{l}25 \cdot 2 \\
11 \cdot 2\end{array}$ \\
\hline $\begin{array}{lll}\text { strapping } & . & . \\
\text { Strapping } & . & . \\
\text { S./W. and crepe } & . \\
\text { S//W. and perspex } & . \\
\text { Others .. } \quad . & .\end{array}$ & $\begin{array}{r}20 \\
1 \\
5 \\
3 \\
3\end{array}$ & $\begin{array}{r}3 \\
14 \\
2 \\
1 \\
6\end{array}$ & $\begin{array}{r}23 \\
15 \\
7 \\
4 \\
9\end{array}$ & $1^{-}$ & $\begin{array}{l}2 \\
7(50 \%) \\
1-\end{array}$ & $\begin{array}{l}10 \cdot 8 \\
10 \\
7 \cdot 2 \\
12 \cdot 7 \\
20\end{array}$ & $\begin{array}{l}32 \cdot 7 \\
31 \cdot 3 \\
21 \\
8 \\
20\end{array}$ & $\begin{array}{c}9 \% \\
47 \% \\
28 \cdot 6 \% \\
-\end{array}$ & $\begin{array}{l}13 \cdot 7 \\
29 \cdot 8 \\
11 \cdot 1 \\
11 \cdot 5 \\
20\end{array}$ \\
\hline Totals & 63 & 62 & 125 & - & - & - & - & - & - \\
\hline
\end{tabular}

* High relapse rate; recovery prolonged; indicates failure of plaster immobilization.

** Mild early cases only

P.T. = physiotherapy. P.W.B. = paraffin wax baths. I.R.R. = infra red rays. S./W. = ultra short wave therapy. Strap. = elastoplast strapping. $\mathbf{P x} .=$ perspex splinting 